\title{
The Use of Antihypertensive and Antiplatelet Drugs on Hospital Stroke Patients
}

\author{
Anggy Rima Putri ${ }^{1}$, Akrom $^{2}$, Budiyono ${ }^{3}$ \\ 1,3 Magister Clinical Pharmacy Program, Ahmad Dahlan University, Indonesia \\ ${ }^{2}$ Department of Pharmacology and Clinical Pharmacy \& Drug information and Crisis Center, Ahmad Dahlan University,
} Indonesia

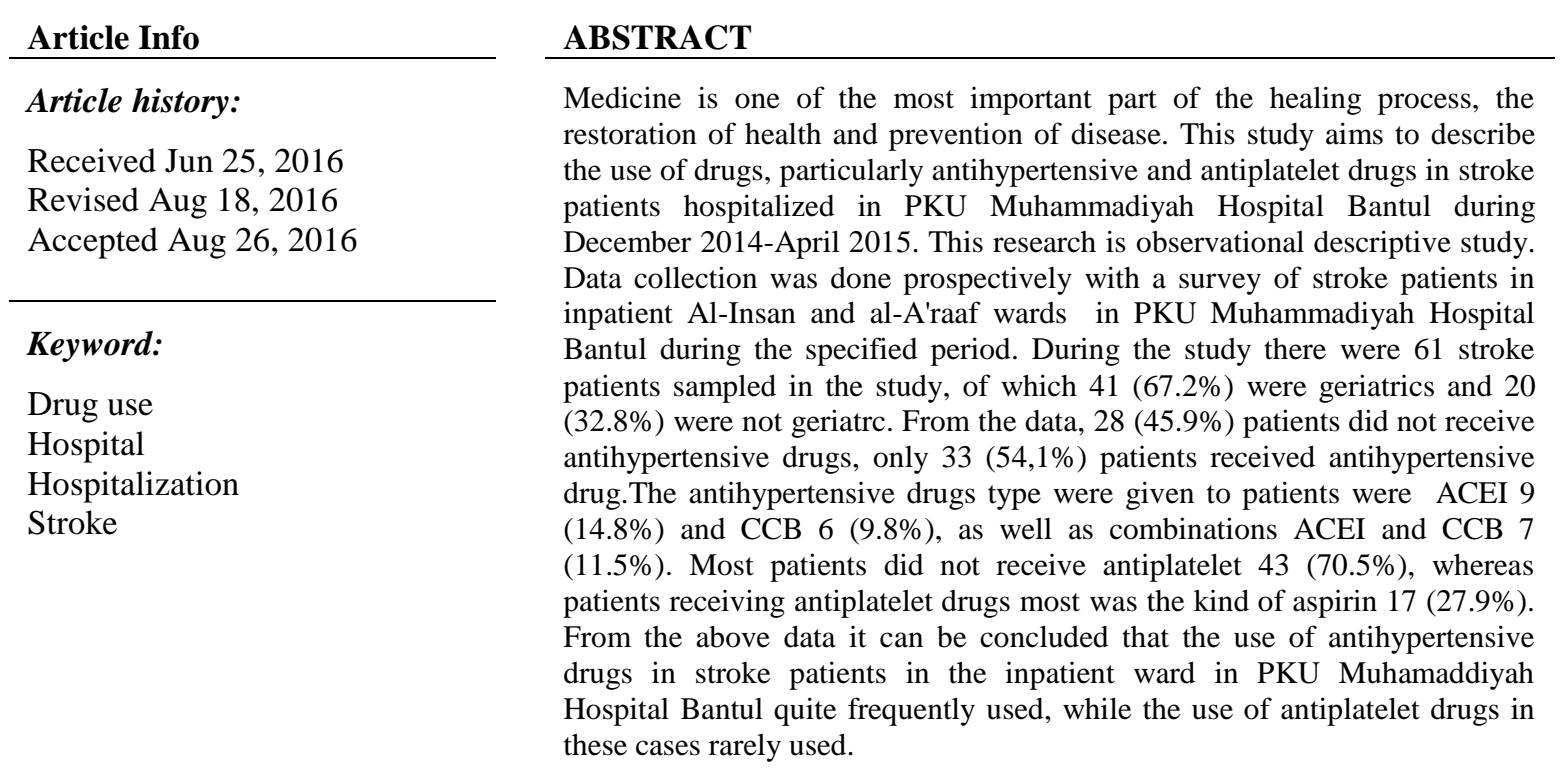

Copyright $(2016$ Institute of Advanced Engineering and Science. All rights reserved.

\section{Corresponding Author:}

Akrom,

Department of Pharmacology and Clinical Pharmacy,

Ahmad Dahlan University,

Street Prof. Dr. Soepomo, Janturan, Umbulharjo, Yogyakarta. Indonesia.

Email: akmaa_uad@yahoo.co.id

\section{INTRODUCTION}

Decision drug use always contains the consideration of benefits and risks. Patients who received the drug at risk of experiencing drug-related problems. The complexity of the disease and drug use, as well as highly individual patient response increasing emergence of drug-related problems [1].

The goal of therapy with medication is the achievement of therapeutic outcome, namely improving the quality of life of patients with minimal risk. In each there is a risk of drug use, whether known or not, called drug misadventure, which included adverse drug reactions and medication errors. Adverse drug reactions are more affected by the condition of the patients, whereas medication errors occur due to human error or weakness of the existing system [2].

One of the diseases which is a medical emergency that can cause physical and mental disabilities, and can cause sudden death was a stroke. Stroke is a cerebrovascular disease is the leading cause of death is often the case in Indonesia. Service centers in neurology Indonesia number of people with circulatory disorders of the brain (GPDO) station is the first of all patient admissions [3], [4]. The prevalence of stroke in Indonesia amounted to 12.1 deaths per 1000 population and which has been diagnosed by health personnel 
was 7 deaths per 1000 population. Stroke causes of death in almost all hospitals in Indonesia, namely 14.5 percent [5].

\section{RESEARCH METHOD}

\subsection{Research tool}

The tool used for research in the form of Case Record Form (CRF).

\subsection{Materials research}

Materials used in the study are primary data and secondary data. The primary data comes from interviews to patients while secondary data derived from the patient's medical record. Information obtained from both primary data and secondary data is then written in the Case Record Form (CRF), which has been created by researchers and has been in legitimate right by the ethics committee of the University of Ahmad Dahlan.

\subsection{Stage of Research}

\subsubsection{Study design}

This is a descriptive observational research. Data were collected data collection was done prospectively with a survey of stroke patients in inpatient Al-Insan and al-A'raaf wards in PKU Muhammadiyah Hospital Bantul during the month of December 2014-April 2015.

\subsubsection{Sampling}

Sample in this study were all patients with stroke in RS PKU Muhammmadiyah Bantul in the study period ie during December 2014-April 2015 were willing to engage in research and included in the inclusion criteria. Researchers conducted a personal approach to the patient or the patient's family to explain the intent and purpose of the study and ask the patient to be willing to become respondents in this study. Before data collection, subject to the approval of the respondents informed consent form signed by the respondents as proof that the respondents willing to participate in research and understand the purpose of the study.

\subsubsection{Operational definitions}

1) Patients in this study were all patients diagnosed stroke with or without comorbidities, who are hospitalized in the wards Al-Insan and al-A'raaf at PKU Muhammadiyah Hospital in Bantul in December 2014-April 2015, until the patient go home, situation improved, referenced, or die.

2) Stroke in this study used a definition of Lionel (2008) [6], ie cerebrovascular disease (blood vessel of the brain), which is marked by the death of brain tissue (cerebral infarction) resulting from reduced blood flow and oxygen to the brain. No second stroke classification, are:

a) Stroke Ischemic or non-hemorrhagic stroke caused by atherosclerosis or thrombus that has blocked a blood vessel to the brain.

b) Haemorrhagic stroke is a stroke caused by a ruptured blood vessel or bleeding in the brain, so that normal blood flow is hampered and blood seeps into the region in the brain and damage.

3) Drug Use in this study are drugs given to inpatients with respect to the stroke their suffered.

\section{RESULTS AND ANALYSIS}

\subsection{General characteristics}

This study discusses the use of antihypertensive and antiplatelet drugs in stroke patients who are hospitalized at PKU Muhammadiyah Hospital in Bantul with a sample of 61 patients. General characteristics of patients by age, gender, education, employment, and payments are presented in Table 1.

According to the Table 1 in mind that the majority of patients aged> 60 years were $41(67.2 \%)$. A total of 34 $(55.7 \%)$ were women. The majority of patients was completed elementary school were $42(68.9 \%)$. A total of $36(59.0 \%)$ work as farmers, employee, and labor. A total of 41 (67.2\%) payment by BPJS/Jamkesmas/Jamkesda. 
Table 1. General Characteristics of Patients in Inpatient Ward PKU Muhammadiyah Hospital in Bantul

\begin{tabular}{llcr}
\hline Characteristics & & Frequency & Percentage \\
\hline Age & $>60$ years & 41 & 67.20 \\
& <60 years & 20 & 32.80 \\
Eex & Man & 27 & 44.30 \\
Education & Woman & 34 & 55.70 \\
& Elementary & 42 & 68.90 \\
Job & Junior & 10 & 16.40 \\
& Senior & 9 & 14.80 \\
& No work & 17 & 27.90 \\
& PNS & 1 & 1.60 \\
Payment & Entrepreneur & 7 & 11.50 \\
& Farmers, Employee, Labor & 36 & 59.00 \\
& Public / Governmental & 12 & 19.70 \\
& BPJS Askes PNS & 7 & 11.50 \\
& BPJS Jamkesmas/Jamkesda & 41 & 67.20 \\
& BPJS Mandiri & 1 & 1.60 \\
\hline
\end{tabular}

\subsection{Clinical characteristics}

Clinical characteristics include the patient arrives at the hospital, the category of stroke, diagnosis status, action MSCT head, RPD Stroke, and smoking history are presented in Table 2.

Table 2. Clinical Characteristics of Patients in inpatient ward PKU Muhammadiyah Hospital in Bantul

\begin{tabular}{llcr}
\hline Characteristics & & Frequency & Percentage \\
\hline Arrived in & $<4$ hours & 33 & 54.10 \\
hospital wards & $>$ 4 hours & 28 & 45.90 \\
Stroke category & Non Hemorrhagic Stroke & 21 & 34.40 \\
& Hemorrhagic Stroke & 7 & 11.50 \\
& Unidentified Stroke & 33 & 54.10 \\
MSCT head & Yes & 28 & 45.90 \\
& No & 33 & 54.10 \\
RPD stroke & Yes & 12 & 19.70 \\
& No & 49 & 80.30 \\
History of & Yes & 3 & 4.90 \\
Smoking & No & 38 & 62.30 \\
& Former smoker & 20 & 32.80 \\
\hline
\end{tabular}

According to the table 2 that more than half of the patients arrived at the hospital < 4 hours by 33 (54.1\%). A total of $33(54.1 \%)$ of stroke was not identified. A total of $33(54.1 \%)$ did not do MSCT head. Most patients with no history of stroke by $49(80.3 \%)$. A total of $38(62.3 \%)$ patients not to smoke.

\subsection{Drug use}

Description of Drug Use in the inpatient ward PKU Muhammadiyah Hospital in Bantul are presented in Table 3. Based on Table 3 is known that all patients did not receive thrombolytic, however, all patients received a neuroprotective. Most patients get the drug neurotrophic 56 (91.8\%). A total of 33 (54.1\%) patients received antihypertensive drugs. Most patients did not receive antiplatelet, only $17(27.9 \%)$ patients receiving antiplatelet drugs. Whereas patients received hemostatic drugs as much as $9(14.8 \%)$.

Table 3. Drug Use in the inpatient ward PKU Muhammadiyah Hospital in Bantul

\begin{tabular}{ccccc}
\hline No & & Drug use & Frequency & Percentage \\
\hline 1 & Thrombolytic & Not use & 61 & 100.00 \\
& & Use & 0 & 0 \\
2 & Neuroprotective & Not use & 0 & 0 \\
& & Use & 61 & 100.00 \\
3 & \multirow{2}{*}{ Neurotrophic } & Not use & 5 & 8.20 \\
& & Use & 56 & 91.80 \\
4 & \multirow{2}{*}{ Antihypertensive } & Not use & 28 & 45.90 \\
& & Use & 33 & 54.10 \\
5 & \multirow{2}{*}{ Antiplatelet } & Not use & 44 & 72.10 \\
& & Use & 17 & 27.90 \\
6 & \multirow{2}{*}{ Hemostatic } & Not use & 52 & 85.20 \\
& & Use & 9 & 14.80 \\
\hline
\end{tabular}




\subsection{Use of antihypertensive drugs and antiplatelet}

Antihypertensive Drug Use and Antiplatelet in stroke patients in the inpatient ward PKU Muhammadiyah Hospital in Bantul are presented in the following Table 4.

Table 4. Drug Use in the inpatient ward PKU Muhammadiyah Hospital in Bantul

\begin{tabular}{ccccc}
\hline No & \multicolumn{2}{c}{ Drug use } & Frequency & Percentage \\
\hline 1 & Antihypertensive & Not use & 28 & 45.90 \\
& & ACEI & 9 & 14.80 \\
& & ARB & 3 & 4.90 \\
& CCB & 6 & 9.80 \\
& & ARB,CCB & 5 & 8.20 \\
& & ARB,BB,CCB & 1 & 1.60 \\
& & ACEI,CCB & 7 & 11.50 \\
& & ACEI, BB, Diuretic & 1 & 1.60 \\
& \multirow{5}{*}{ Antiplatelet } & ACEI,ARB & 1 & 1.60 \\
& & Not use & 43 & 70.50 \\
& & Aspirin & 17 & 27.90 \\
& & Cilostazole & 1 & 1.60 \\
\hline
\end{tabular}

Based on table 4 is known that as many as $28(45.9 \%)$ patients did not receive antihypertensive drugs, whereas most patients antihypertensive drugs given to patients is the type of ACEI 9 (14.8\%) and CCB $6(9.8 \%)$, as well as combinations ACEI and CCB 7 (11.5\%). Most patients do not receive antiplatelet $43(70.5 \%)$, whereas patients receiving antiplatelet drugs aspirin most is the kind of $17(27.9 \%)$.

Hypertension in patients with ischemic stroke, there is evidence that blood pressure will rise generally occurs during ischemic stroke and can last several days. The increase in blood pressure (highnormal blood pressure) is needed to maintain the blood flow of the brain after a stroke occurs and going down slowly by itself without treatment. However, the blood pressure is too high cannot be left, so the need for giving of antihypertensive in stroke patients with certain conditions. In ischemic stroke systolic blood pressure $>220 \mathrm{mmHg}$ or diastolic blood pressure $>110 \mathrm{mmHg}$ should be given antihypertensive drugs [7]-[9]. In a hemorrhagic stroke decreased blood pressure will reduce the risk of re-bleeding or bleeding that is continuous, but the area around the hematoma increased ischemic brain because auto regulation in this area has been lost. On this basis antihypertensive drugs are given if the systolic pressure $>180 \mathrm{mmHg}$ or diastolic blood pressure> $100 \mathrm{mmHg}$ [10]. According Mancia (2010) advocated the reduction of blood pressure as early as possible in intracerebral hemorrhage with mean arterial blood pressure $>145 \mathrm{mmHg}$, to prevent rebleeding, reduction of intracranial pressure and brain edema [11].

Antiplatelet therapy aims to prevent a secondary stroke in ischemic stroke by preventing clot formation. Giving antiplatelet could as a single agent or in combination with consideration of the advantages and disadvantages according to the patient's condition [12]. In this study antiplatelet drugs most commonly used is aspirin, where aspirin is an antiplatelet first choice for preventing the occurrence of ischemic stroke. The use of aspirin can reduce death and disability caused by ischemic stroke. The International Stroke Trial (IST), explains that aspirin $300 \mathrm{mg}$ per day can significantly reduce stroke recurrence [13]. In the acute treatment of ischemic stroke cerebral blood flow restoration to remove the blockage/clots and stop cellular damage associated with ischemic/hypoxic, is the first medical treatment that should be given to stroke patients. Giving antiplatelet (aspirin) is recommended for every acute ischemic stroke [14].

\section{CONCLUSION}

The results of this study indicate that the use of antihypertensive drugs in stroke patients in the inpatient ward PKU Muhamaddiyah Hospital Bantul used often enough, but not so with the use of antiplatelet drugs which in this case is still rarely used. This is probably related to the risk of gastroenteritis, especially for geriatric patients, as well as the type of stroke suffered by the patient, where giving of antiplatelet recommended in treatment of ischemic stroke, but are contraindicated when given in hemorrhagic stroke because it can increase the risk of bleeding. However, giving of antiplatelet still recommended for any cases of acute ischemic stroke, especially if the benefits received is greater than the risk/harm that may be caused. 


\section{REFERENCES}

[1] AHA, "Medication Errors in Acute Cardiovascular and Stroke Patients a Scientific Statement From the American Heart Association," Circulation, vol. 121, pp. 1664-1682, 2010.

[2] L. T. Kohn, J. M. Corrigan, M. S. Donaldson, "Error in Health Care: A Leading Cause of Death and Injury," in L. T. Kohn, "To Err is Human, Institute of Medicine," National Academy Press, Washington D.C., pp. 26-47, 2000.

[3] M. A. Hussain, A. Al Mamun, S. A. Peters, et al., "The Burden of Cardiovascular Disease Attributableto Major Modifiable Risk Factors in Indonesia," J Epidemiol, pp. 1-7, 2016.

[4] Ministry of Health Republic of Indonesia, "Indonesia Health Profile 2013," Jakarta, Indonesia, 2014.

[5] The National Institute of Health Research and Development, "Result of National Basic Health Research (RISKESDAS 2007), Ministry of Health, Republic of Indonesia, Jakarta, 2013.

[6] G. Lionel, "Lecture Notes: Neurology, Ed. VIII," Jakarta, Erlangga, 2008.

[7] Ministry of Health Republic of Indonesia, "Stroke Guideline," Ministry of Health, Republic of Indonesia, Jakarta, 2013.

[8] The European Stroke Organization (ESO) Executive Committee and the ESO Writing Committee, "Guidelines for Management of Ischaemic Stroke and Transient Ischaemic Attack," 2008. www.esostroke.org.

[9] J. Potter, A. Mistri, F.Brodie, et al., "Controlling Hypertension and Hypotension Immediately Post Stroke (CHHIPS) - a randomised controlled trial," Health Technology Assessment, vol/issue: 13(9), 2009.

[10] PERDOSSI, “The 2011 Stroke Guideline," Indonesia Neurologist Doctor Association, Jakarta, 2011.

[11] G. Mancia, "Effects of Intensive Blood Pressure Control in the Management of Patients With Type 2 Diabetes Mellitus in the Action to Control Cardiovascular Risk in Diabetes (ACCORD) Trial," Circulation, vol. 122, pp. 847-849, 2010.

[12] D. Y. Huang, W. G. Eisert, "Chance Trial Early Short-Term Dual Antiplatelet Treatment for Stroke Prevention," Stroke, vol. 44, pp. 3623-3624, 2013.

[13] Dipiro, et al., "Pharmacotherapy A Pathopysiologic Approach," Mc - Graw Hill, New York, vol. 452, pp. 456-459, 2005.

[14] K. Kikuchi, H. Uchikado, M. Morioka, et al., "Clinical Neuroprotective Drugs for Treatment and Prevention of Stroke," Int. J. Mol. Sci, vol. 13, pp. 7739-7761, 2012. doi: 10.3390/ijms13067739. 